\title{
Transporte de Sedimentos e Variação da Linha de Costa em Curto Prazo na Praia de Maracaípe (PE), Brasil *
}

\author{
Sediment Transport and Short Term Coastline Variation at \\ Maracaípe Beach (PE), Brazil
}

\author{
Renê Jota Arruda de Macedo ${ }^{\circledR, ~} 1$, Valdir do Amaral Vaz Manso ${ }^{1}$, Natan Silva Pereira ${ }^{1}$, \\ Lucy Gomes de França ${ }^{1}$
}

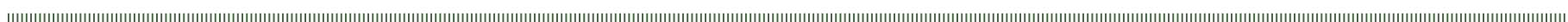

\section{RESUMO}

O litoral sul de Pernambuco nos últimos anos vem passando por um processo de expansão urbana que está sendo acelerado pelo desenvolvimento econômico da região. Alguns trechos são naturalmente vulneráveis à erosão enquanto outros sofrem problemas erosivos decorrentes da ocupação irregular da zona costeira. Anualmente, são reportados processos erosivos na praia de Maracaípe. Este trabalho tem como objetivo caracterizar o transporte de sedimentos através da análise sedimentar, morfológica e variaçáo da linha de costa em curto prazo da praia de Maracaípe a fim de entender a dinâmica sedimentar desta regiáo. Foram realizados perfis topográficos no período de dezembro/2009 a dezembro/2010, coleta de sedimentos durante o verão e o inverno e análise da variação da linha de costa por imagens orbitais. As larguras e volumes da praia extraídas dos perfis topográficos mostraram que há uma tendência de transporte de sul para norte ao longo do ano, com algumas inversōes de sentido em determinados períodos. Os setores 1 e 4 são compostos por areia fina e os setores 2 e 3 areia média, moderadamente a bem selecionada. A linha de costa apresentou, na primeira série histórica, progradação, com retrogradação no período seguinte e por fim progradação novamente, sendo que o setor 4 acumulou um recuo constante em todo o período. As variaçóes da largura de praia e da linha de costa indicam que há um padrão de circulaçáo celular dos sedimentos nos trechos centrais da praia sendo necessário um trabalho em escala maior com uma malha de dados mais detalhada. O processo erosivo na região está associado a fatores naturais e antrópicos, sendo o primeiro relacionado à dinâmica estuarina do rio Maracaípe e o segundo a ocupação da pós-praia. Recomenda-se monitoramentos de maior espaço de tempo para a área de estudo de modo que gere subsídios ao gerenciamento costeiro da regiáo para se estabelecer limites de uso e ocupaçáo da orla.

Palavras-chave: Maracaípe; Perfis de Praias; Variação da linha de costa; Transporte de sedimentos.

\section{ABSTRACT}

The south coast of Pernambuco has been experiencing an urban expansion process in recent years that it is being accelerated by the economic development of the region. Some stretches are naturally vulnerable to erosion while others are under erosion process due to irregular occupation of the coastal zone. Annually, problems related to erosion processes are reported at Maracaipe beach. The aim of this work is to characterize the sediment transport through sedimentological, morphological and short term shoreline variation analysis of the Maracaipe beach, in order to clarify the sedimentological dynamics of this region. It was carried out topographic surveys of the beach from December of 2009 to December

@ - Corresponding author: renemacedo@hotmail.com

1 - Universidade Federal de Pernambuco, LGGM - Laboratório de Geologia e Geofísica Marinha, Departamento de Geologia, Avenida Acadêmica Hélio Ramos s/no cep 50.740-530 Recife, Pernambuco, Brasil. 
of 2010, sediments sampling during summer and winter and shoreline variation analysis using orbital images. The beach widths and volumes extracted from the beach profiles showed a trend transport from south to northward, with some inversions of the direction in some periods along the year. The sectors 1 and 4 are constituted by fine sands and the sectors 2 and 3 by medium sands, moderately to well sorted. The coastline study had presented progradation in the first historical series, then a retreat in the second one and finally progradation in the last one, except for the sector 4 that amounted a constant retreat in whole historical series. The shoreline variations and the beach widths indicates a sediment coastal cell circulation pattern at the central stretches of Maracaipe beach. So it is necessary a new study in a major scale to comprises a more detailed datanet. The erosion processes in the region are associated to estuarine dynamic of the Maracaipe river and anthropic factors such as irregular backshore occupation. A major time scale monitoring is recommended so that generates subsides to coastal management of the region in establishing delimitations in the use and occupation of the coast.

Keywords: Maracaipe; Beach profile; Shoreline variation; Sediment transport.

\section{INTRODUÇÃO}

A erosão caracteriza-se pela remoção de material sedimentar (Muehe, 1996). Em praias arenosas é um processo natural que resulta da dinâmica entre diversos fatores físicos sobre a praia: variaçôes relativas do nível do mar, energia das ondas e da disponibilidade e tipo de sedimentos (Toldo Jr. et al., 2005). No Brasil, em zonas costeiras urbanas, este processo pode ser acelerado por intervenção do homem nos processos costeiros (Muehe, 2006) e pressão antrópica de cunho sócio-econômico, ou seja, ocupação e uso destas zonas sem planejamento prévio (Souza, 2009).

$\mathrm{O}$ processo de erosão que ocorre nas praias do litoral pernambucano é um fator que vem se agravando nos últimos anos. Naturalmente, alguns trechos são vulneráveis à erosão pelas características ambientais inerentes como o baixo aporte sedimentar proveniente dos rios costeiros para as praias adjacentes (Araújo et al., 2007) e a largura reduzida da plataforma continental interna - média de $35 \mathrm{~km}$ (Manso et al., 2003). Segundo Araújo et al. (2007) este estreitamento da plataforma dificulta o armazenamento de sedimentos para remobilização. Além disso, a forma de ocupação desordenada que se configura ao longo do litoral de Pernambuco dá início ou acentua os processos erosivos correntes, pois a impermeabilização do ambiente praial acaba alterando o balanço sedimentar, como apontam Costa et al. (2008) em seus estudos na praia de Boa Viagem (Pernambuco).

As praias do núcleo metropolitano do Recife situadas no litoral sul do estado de Pernambuco compreendem os municípios de Jaboatão dos Guararapes, Cabo de Santo Agostinho e Ipojuca (Figura 1).

Nos últimos anos esta região vem sendo alvo de grande especulação imobiliária em detrimento do desenvolvimento de atividades turísticas e industriais na regiâo do porto de Suape, situado entre os municípios do Cabo de Santo Agostinho e Ipojuca. Por conta disso, ocorre uma acentuada expansão urbana, a qual se reflete no número de habitantes. De acordo com dados do Instituto Brasileiro de Geografia e Estatística (IBGE) em 1996 a população desses municípios somava 719.209 habitantes e em 2010 saltou para 910.364 habitantes, ou seja, um crescimento populacional de aproximadamente $26,57 \%$. Associado a isto, a falta de planejamento e fiscalização do modo de ocupação e uso do ambiente praial vem acarretando problemas ambientais que podem trazer sérias consequências para o sistema praial e as atividades humanas na região.

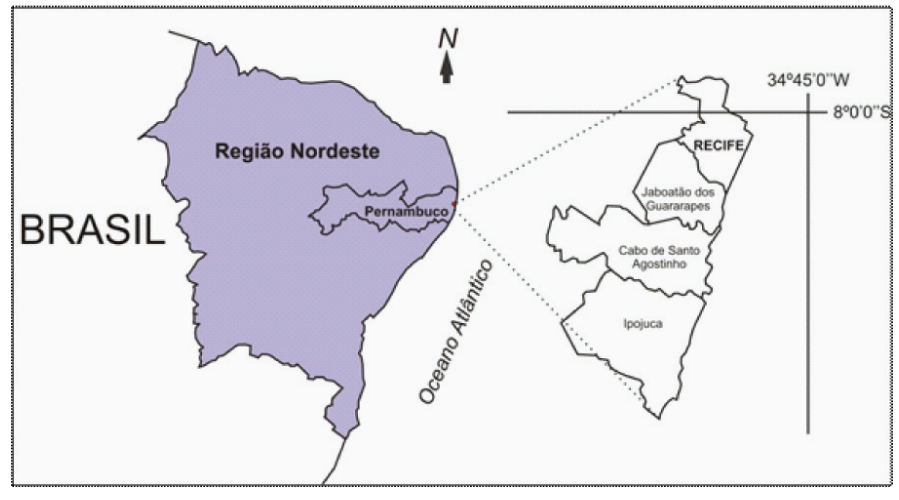

Figura 1. Mapa dos municípios do núcleo metropolitano do Recife que compreendem o litoral sul de Pernambuco.

Figure 1. Map of the municipalities of the metropolitan region of Recife which encompass the south coast of Pernambuco.

Com foco em diagnosticar as causas e os efeitos dos processos erosivos neste setor do litoral pernambucano, alguns trabalhos foram realizados por meio de estudos de caracterização geoambiental do ambiente praial: Coutinho et al. (1997); Borba (1999); Madruga Filho (2004), Araújo et al. (2007); Almeida, (2008). Em geral, estes trabalhos apontam as atividades humanas de forma desordenada sobre o sistema costeiro como principal agente causador dos problemas relacionados com a erosão marinha. $\mathrm{Na}$ região da praia de Maracaípe, no município de Ipojuca, anualmente são reportadas ameaças de perda de patrimônio devido à erosão costeira recorrente e acentuada nos períodos chuvosos. Isto decorre da ocupaçáo de casas de veraneio e estabelecimentos comerciais na pós-praia que impede o intercâmbio de sedimentos entre a praia e antepraia. São poucos os trabalhos que podem ser encontrados na literatura científica sobre os processos costeiros atuantes naquela região com exceção dos estudos de Sobral et al. (1998) que caracteriza os estados morfodinâmicos e a sedimentologia da faixa de praia bem como a erosão na regiâa do Pontal de Maracaípe; Manso et al. (2003) realizou um levantamento da morfologia e sedimentologia da plataforma interna; Macêdo et al. (2010) realizaram um trabalho de caracterização ambiental e morfodinâmica da praia de Maracaípe. Mesmo assim, faltam análises mais específicas do comportamento morfológico da praia, variação da linha de costa e transporte de sedimentos 
em curto e médio prazo. As variaçóes morfológicas de curto e médio prazo ocorrem nas escalas de tempo instantânea e de evento (Cowell \& Thom, 1997) que envolvem mudanças morfológicas associadas a pequenos ciclos de forças (ondas e marés) até mudanças sazonais destas forçantes. Este processo de variação compreende períodos de tempo desde segundos a anos enquanto que espacialmente varia de centímetros a centenas de metros. Cowell et al. (2003) enfatiza que esses processos estão condicionados a dinâmica sedimentar local. Para variaçóes de linha de costa Crowell et al. (1993) estimaram mudanças de curto prazo àquelas que ocorrem a um período de tempo menor que 10 anos.

$\mathrm{O}$ presente estudo tem como objetivo preencher esta lacuna do conhecimento sobre a dinâmica praial da regiáo na escala de curto e médio prazo com intuito de mitigar o escasso conhecimento a respeito da dinâmica do transporte de sedimentos e variação da linha de costa na praia de Maracaípe. Através disso, fornecer dados para o gerenciamento costeiro no que diz respeito às políticas de uso $\mathrm{e}$ ocupação do solo em praias. Thom \& Short (2006) destacam a importância do uso do conhecimento da geomorfologia costeira ao gerenciamento costeiro como instrumento para o planejamento de uso destas áreas.

\section{2. ÁREA DE ESTUDO}

A praia de Maracaípe está localizada no município de Ipojuca no litoral sul da Regiáo Metropolitana do Recife, a $70 \mathrm{~km}$ da capital Recife, no Estado de Pernambuco, Brasil. Em forma de enseada, possui uma orla de aproximadamente $3,8 \mathrm{~km}$ de extensão e está localizada no mapa (Figura 2) entre as coordenadas UTM $278807 \mathrm{mE}-279841 \mathrm{mE}$ e $9054978 \mathrm{mN}-9058939 \mathrm{mN}$, que forma um polígono, no sistema de referência SAD 1969. Limita-se a Norte com a praia de Porto de Galinhas e a Sul com o rio Maracaípe. A faixa de praia ainda apresenta vegetação rasteira nativa nos trechos onde não há ocupação da pós-praia, principalmente da porção norte para o setor intermediário da área de estudo. Os perfis praiais, segundo Macêdo (2011), apresentam características morfodinâmicas de praias intermediárias embarreiradas a dissipativas embarreiradas (Masselink \& Short, 1993). Sendo que nos setores extremos há ocorrência de terraços de baixamar no período de verão.

$\mathrm{Na}$ plataforma interna adjacente estão presentes recifes dispostos paralelamente à linha de costa nos extremos norte e sul da regiáo de Maracaípe, de modo que o setor central da praia é exposto ao mar aberto.

O clima que predomina na regiáo é o do tipo Ams', que é caracterizado pelo tipo megatérmico, com temperatura do ar sempre superior a $18^{\circ} \mathrm{C}$. O índice pluviométrico anual total é em média acima de $2000 \mathrm{~mm}$ com chuvas de monçóes durante quase todo o ano, com uma estação seca bem definida e relativamente curta durante o outono. A temperatura média anual para a regiấo é de $25,5^{\circ} \mathrm{C}$. As temperaturas mais elevadas são observadas durante os meses de primavera (outubro, novembro e dezembro) e veráo. No inverno (junho, julho e agosto), a redução da temperatura não é significativa apresentando uma média de $23^{\circ} \mathrm{C}$.

Segundo dados estatísticos do CPTEC/INPE (Centro de Previsão e Estudo de Tempo e Estudos Climáticos e Instituto

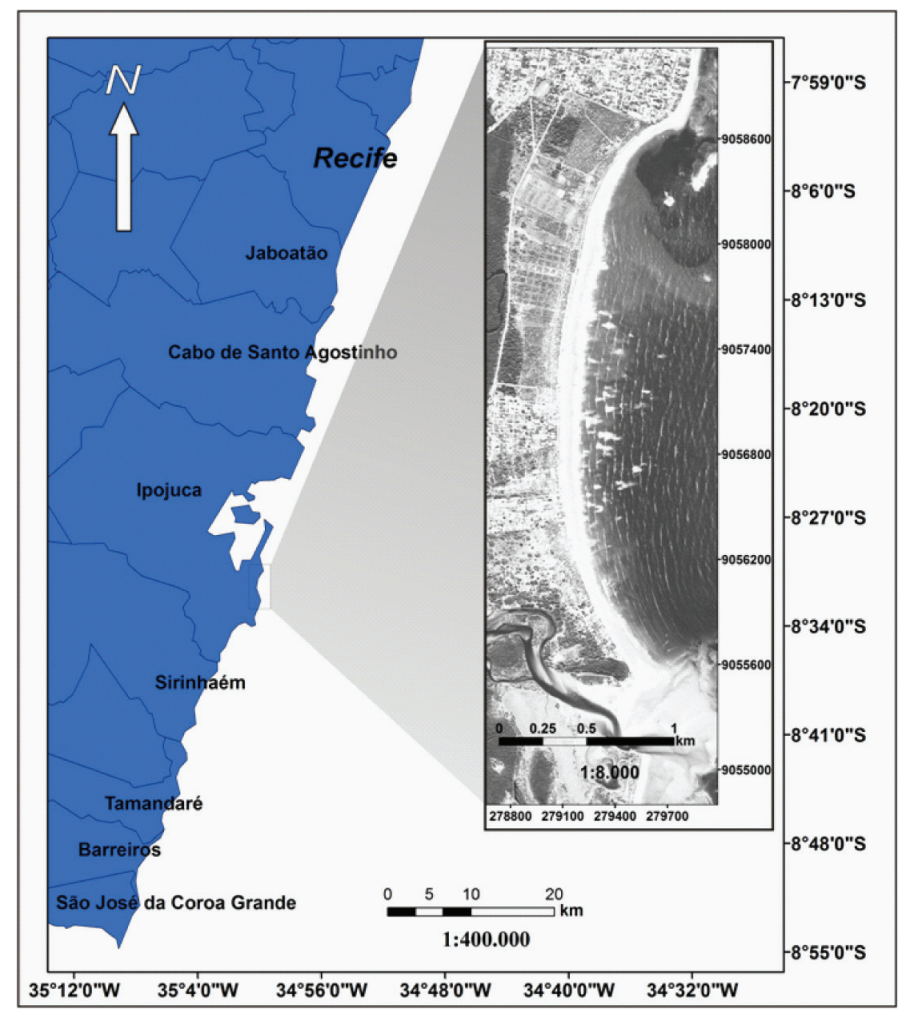

Figura 2. Localização da praia de Maracaípe.

Figure 2. Maracaipe beach location.

Nacional de Pesquisas Espaciais) da área de Ipojuca, relativos ao período de dezembro/2009 a dezembro/2010, os ventos dominantes na regiấo são os de direção E-SE. Durante o verão, a incidência dos ventos são os alísios predominantes de $\mathrm{E}$ com velocidades médias de $5,6 \mathrm{~m} / \mathrm{s}$. No regime de inverno, a incidência maior de direção permanece a de SE, com velocidades médias na faixa de 5,74 a $6,58 \mathrm{~m} / \mathrm{s}$. Manso (2003) afirma que o regime de ventos em toda regiáo costeira caracteriza-se por ser bastante regular e sazonal, soprando em $90 \%$ do tempo do setor E-SE, com velocidades médias de 3 a $5 \mathrm{~m} / \mathrm{s}$.

O regime de maré é do tipo mesomaré $(2 \mathrm{~m}-4 \mathrm{~m})$ de acordo com a classificação proposta por Davies (1964), com curva sinusoidal que possibilita a execução de cálculos de previsão de altura da maré a qualquer hora do dia. O clima de ondas da região é caracterizado por ondas com altura significativa média $\left(\mathrm{H}_{\mathrm{s}}\right)$ de $1,61 \mathrm{~m}$, período médio $(\mathrm{T})$ de $6,7 \mathrm{~s}$, as quais incidem durante o verão de ENE e inverno ESE (Assis, 2007).

O sistema de correntes costeiras segundo Bittencourt et al. (2005) é caracterizado por uma deriva litorânea que predomina de S-N na costa nordestina do Brasil.

\section{MATERIAIS E MÉTODOS}

Para identificar o transporte de sedimentos e o comportamento morfológico da praia foram realizadas campanhas mensais de levantamento de perfis topográficos da orla de Maracaípe, compreendendo o período de dezembro de 2009 a dezembro de 2010. No total, 4 perfis topográficos (P1, P2, P3 e P4) foram traçados com uso de régua e 
nível (Manso et al., 2011), dispostos em espaços (setores) intercalados que variaram de $800 \mathrm{~m}$ a $1000 \mathrm{~m}$, de forma que contemplassem todo o perímetro da praia (Figura 3), realizados sempre na baixamar. Tomou-se como referenciais de nível (RN) de cada perfil estruturas fixas (árvores e postes) localizadas próximas a faixa de praia. Os dados obtidos em campo foram lançados em uma planilha para geração de gráficos, cálculo do volume do perfil subaéreo e da medida de variaçáo da largura da faixa de praia, que foi considerada como a base do referencial de nível fixado na costa até a linha d'água (nível do mar). A partir destes dados será possível inferir a dinâmica do transporte de sedimentos, segundo o padrão das larguras dos perfis medidos como realizado por Souza (2007). O autor determinou células de deriva nas praias do estado de São Paulo (Brasil) assumindo que o estreitamento da largura de praia indica erosão ao passo que o alargamento indica deposição.

As medidas de ondas foram coletadas nos mesmos locais dos perfis topográficos considerando-se os seguintes parâmetros de acordo com Muehe (1996) pelo método de observação visual: altura da onda na arrebentação $\left(\mathrm{H}_{\mathrm{b}}\right)$ em metros e tipo de arrebentação. Uma régua graduada foi colocada no ponto de maior recuo do espraiamento enquanto que as medidas eram realizadas por um observador na face de praia mirando a crista da onda com a linha do horizonte, conforme (Muehe, 1996). No mínimo, 10 visualizaçóes de cada ponto foram executadas fazendo-se em seguida uma média aritmética simples além da observação do tipo de arrebentação predominante em cada setor. Os dados de onda em águas profundas $\left(\mathrm{H}_{\mathrm{s}}\right)$ foram obtidos a partir do trabalho de Assis (2007).

Para caracterização sedimentar foram feitas amostragens de sedimentos em cada transecto topográfico sobre duas morfologias: pós-praia e estirâncio. Em seguida, foram realizadas análises granulométricas a fim de obter os

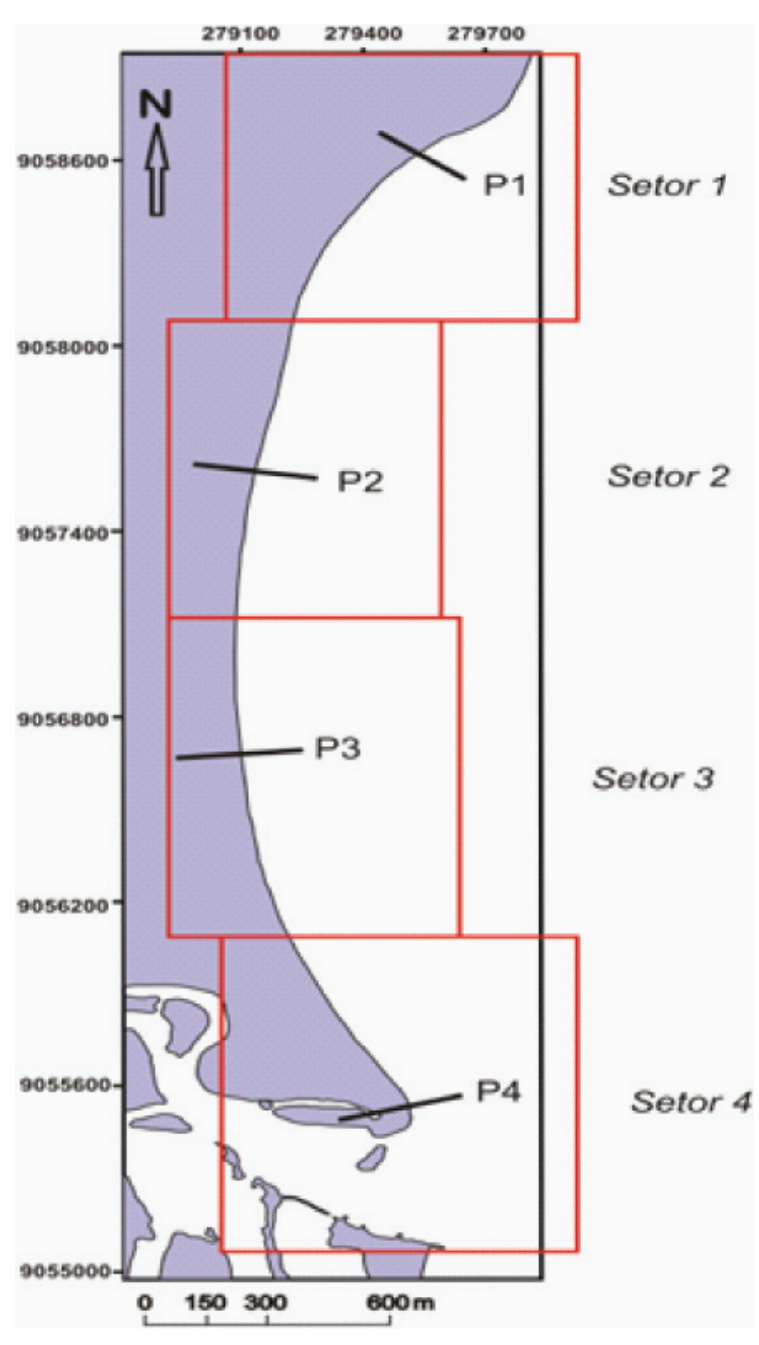

Figura 3. Localização dos perfis topográficos.

Figure 3. Topographic profiles localization.

Tabela 1. Dados de largura de praia e volume dos perfis.

Table 1. Beach width data and volume profile.

\begin{tabular}{l|l|l|l|l|l|l|l|l}
\hline Perfil & \multicolumn{2}{l|}{ P1 } & \multicolumn{2}{l|}{ P2 } & \multicolumn{2}{l|}{ P3 } & \multicolumn{2}{l}{ P4 } \\
\hline Mês & $\begin{array}{l}\text { Largura } \\
(\mathrm{m})\end{array}$ & $\begin{array}{l}\text { Volume } \\
\left(\mathrm{m}^{3} / \mathrm{m}\right)\end{array}$ & $\begin{array}{l}\text { Largura } \\
(\mathrm{m})\end{array}$ & $\begin{array}{l}\text { Volume } \\
\left(\mathrm{m}^{3} / \mathrm{m}\right)\end{array}$ & $\begin{array}{l}\text { Largura } \\
(\mathrm{m})\end{array}$ & $\begin{array}{l}\text { Volume } \\
\left(\mathrm{m}^{3} / \mathrm{m}\right)\end{array}$ & $\begin{array}{l}\text { Largura } \\
(\mathrm{m})\end{array}$ & $\begin{array}{l}\text { Volume } \\
\left(\mathrm{m}^{3} / \mathrm{m}\right)\end{array}$ \\
\hline Dez/09 & 22,5 & 38,80 & 50,8 & 128,46 & 27,8 & 45,28 & - & 63,07 \\
\hline Jan/10 & 31,3 & 49,09 & 56,0 & 135,82 & 36,5 & 67,78 & 56,1 & 73,67 \\
\hline Fev/10 & 31,8 & 50,41 & 53,6 & 125,44 & 35,4 & 63,09 & 42,9 & 47,37 \\
\hline Mar/10 & 34,5 & 56,84 & 61,2 & 147,77 & 39,4 & 75,09 & 43,6 & 40,34 \\
\hline Abr/10 & 30,9 & 48,21 & 55,3 & 149,15 & 33,5 & 70,24 & 30,7 & 29,50 \\
\hline Mai/10 & 27,7 & 42,77 & 58,4 & 146,41 & 29,0 & 50,89 & 32,4 & 29,73 \\
\hline Jun/10 & 30,2 & 43,68 & 49,1 & 130,57 & 29,7 & 60,58 & 31,2 & 25,04 \\
\hline Jul/10 & 32,6 & 47,95 & 48,6 & 120,59 & 30,3 & 54,58 & 32,5 & 25,43 \\
\hline Ago/10 & 33,7 & 46,26 & 46,0 & 116,66 & 28,0 & 50,94 & 35,0 & 29,09 \\
\hline Set/10 & 34,6 & 49,69 & 40,1 & 101,77 & 34,5 & 62,91 & 39,2 & 31,45 \\
\hline Out/10 & 34,5 & 53,10 & 51,1 & 120,25 & 38,6 & 66,58 & 43,5 & 36,16 \\
\hline Dez/10 & 32,3 & 50,26 & 54,5 & 127,58 & 35,0 & 71,71 & 45,8 & 43,90 \\
\hline
\end{tabular}


parâmetros estatísticos. Os dados das fraçôes granulométricas foram plotados no software SYSGRAN versão 3.0 (Camargo 2006), obtendo-se os parâmetros estatísticos do diâmetro médio, grau de seleção e assimetria segundo as equaçóes de Folk \& Ward (1957). Os períodos de coleta de sedimentos ocorreram nos meses de dezembro de 2009, janeiro e fevereiro de 2010 e junho, julho e agosto de 2010. Os três primeiros meses correspondem ao período seco e os três últimos ao período chuvoso. Este período de amostragem foi escolhido em detrimento do regime pluviométrico da região, pois são nestas épocas do ano em que, provavelmente, ocorram as mais intensas variaçóes morfológicas dos perfis praiais.

Para análise da linha de costa numa escala de tempo de curto prazo (Stive et al., 2002) foram utilizadas imagens do sensor Quickbird disponibilizadas pelo Google earth. No total foram 4 imagens cujas datas são de: 01/09/2009, 15/10/2009, 21/02/2010 e 26/06/2010; sendo todas georreferenciadas no datum SAD 1969 por pontos de controle previamente obtidos em campo. Em seguida foi selecionado um indicador da linha de costa, que no presente estudo optou-se pela interface entre a praia seca e úmida (Boak \& Turner, 2005) como referencial de análise, pois esta apresentou-se como um bom indicador discernível em todas as imagens disponíveis. Em seguida, as linhas de costas de cada imagem foram vetorizadas e sobrepostas. Transectos foram traçados sobre a localização geográfica de cada perfil nas imagens de modo que fosse possível realizar as medidas de avanço e recuo da linha de costa de todas as imagens.

\section{RESULTADOS E DISCUSSÃO}

\subsection{Perfis Topográficos: Largura de Praia e Volume}

Evidenciou-se uma dinâmica bastante variada nos 4 perfis topográficos medidos ao longo do período de estudo em suas larguras e volumes (Tabela 1), bem como morfológicas (Figura 4).

No mês de dezembro de 2009 o perfil 1, apresentou uma faixa de praia muito estreita com $22,5 \mathrm{~m}$, aumentando sua largura nos meses subseqüentes. Ao longo do monitoramento o perfil manteve-se estável tanto no seu volume quanto na largura de praia, com média de $48,08 \mathrm{~m}^{3} / \mathrm{m}$ linear e 31,38 $\mathrm{m}$, respectivamente. No perfil 2 a largura de praia variou entre $50 \mathrm{~m}$ e $60 \mathrm{~m}$ entre dezembro de 2009 e junho de 2010, sendo que a partir de julho houve um estreitamento, atingindo 40,1 m de largura em setembro de 2010. Este foi o maior recuo monitorado, sendo também o menor volume de sedimentos calculado, $101,77 \mathrm{~m}^{3} / \mathrm{m}$. Estas maiores taxas de retração apresentadas ocorreram no período chuvoso o que pode indicar que o perfil praial tenha se adaptado às novas condiçóes do clima de ondas quando os ventos sopram mais intensos e a altura de onda é maior nesta época. A faixa de praia para este ponto apresentou média de $52,05 \mathrm{~m}$, sendo que no último mês, dezembro de 2010, a largura foi de $54,5 \mathrm{~m}$.

O perfil 3 obteve uma média de largura praial de 33,14 $\mathrm{m}$, um pouco maior que $\mathrm{P} 1$ e muito menor que $\mathrm{P} 2$. A largura reduzida deve-se a ocupação irregular, onde há claramente assentamentos de diversos equipamentos turísticos sobre o ambiente praial. Neste trecho, anualmente entre os meses de junho e agosto, que correspondem ao período chuvoso com

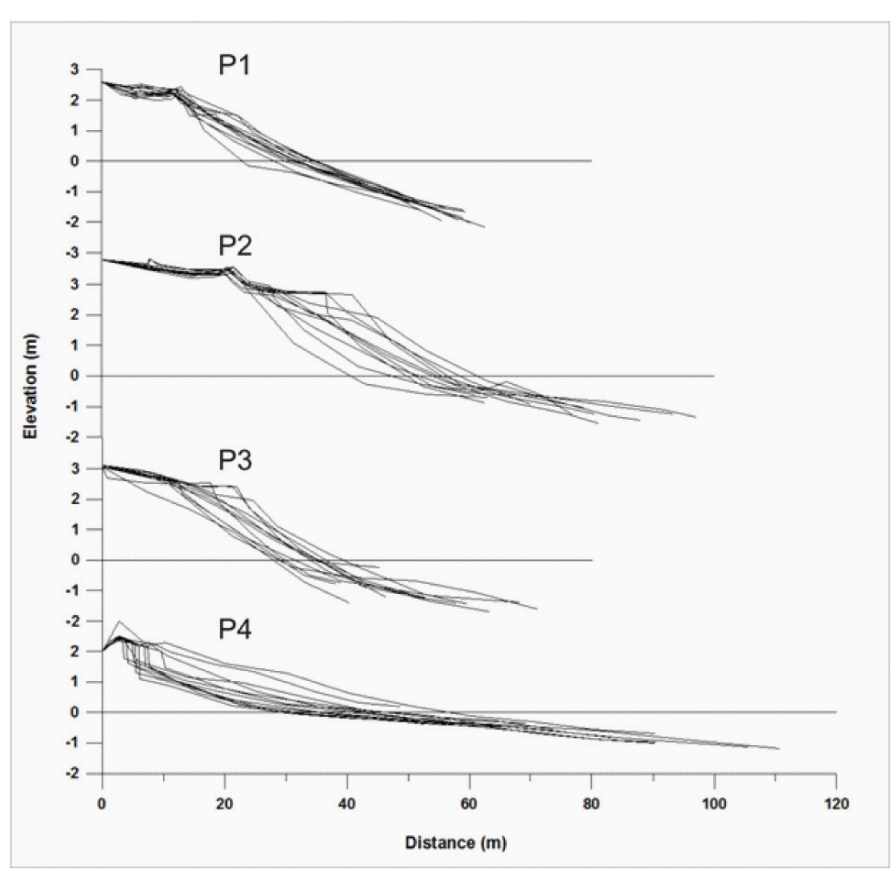

Figura 4. Perfis topográficos medidos entre os meses de dezembro/2009 a dezembro/2010.

Figure 4. Topographic profiles measured from december/2009 to december/2010.

ventos mais fortes e ondas de maior amplitude (Macêdo, 2011), é reportada pela populaçáo local uma acentuada erosão do perfil praial de modo que a própria população realiza medidas paliativas (aterramento da área erodida com sedimentos de outros trechos da praia) para conter este processo erosivo. A escarpa erosiva formada próxima as construçóes situadas na pós-praia é uma ameaça recorrente chegando a afetar o acesso à praia nesta região, além de por em risco os estabelecimentos ali situados. O volume médio de sedimentos do perfil 3 ficou em torno de $61,63 \mathrm{~m}^{3} / \mathrm{m}$ linear sendo que ao longo de um ano a variação deste volume ficou entre $50 \mathrm{~m}^{3} / \mathrm{m} \mathrm{e} 70 \mathrm{~m}^{3} / \mathrm{m}$. O perfil 4 apresentou uma largura de praia média de $39,35 \mathrm{~m}$ com a maior variação morfológica, se comparado com os demais, entre $30,7 \mathrm{~m}$ e $56,1 \mathrm{~m}$. Seu volume seguiu a mesma tendência, alcançado valores máximos de $73,67 \mathrm{~m}^{3} / \mathrm{m}$ linear, em janeiro de 2010 , e mínimos de $25,04 \mathrm{~m}^{3} / \mathrm{m}$ em junho de 2010 , sendo a média para o período monitorado de $39,56 \mathrm{~m}^{3} / \mathrm{m}$. Ao comparar as variaçóes de largura de praia de cada perfil, é possível identificar um padrão de deposiçấo ao longo da costa (Figura 5) para o período monitorado.

A comparação dos dados de P1 e P2 mostra que nos meses de dezembro/2009 a março/2010 há um alargamento da faixa de praia que indica aumento de volume de sedimentos para esta área de Maracaípe. O mesmo ocorre em P3, seguindo a tendência muito próxima a de P2. Contrariamente, o P4 segue uma forte retração em sua largura, o que indica, possivelmente, que os sedimentos deste setor tenham migrado para as áreas adjacentes depositando-se principalmente nos setores ao norte da praia, perfis P1, P2 e P3. A forte retrogradação ocorrida em $\mathrm{P} 4$ durante o período seco pode estar relacionada, além do sentido da deriva litorânea 


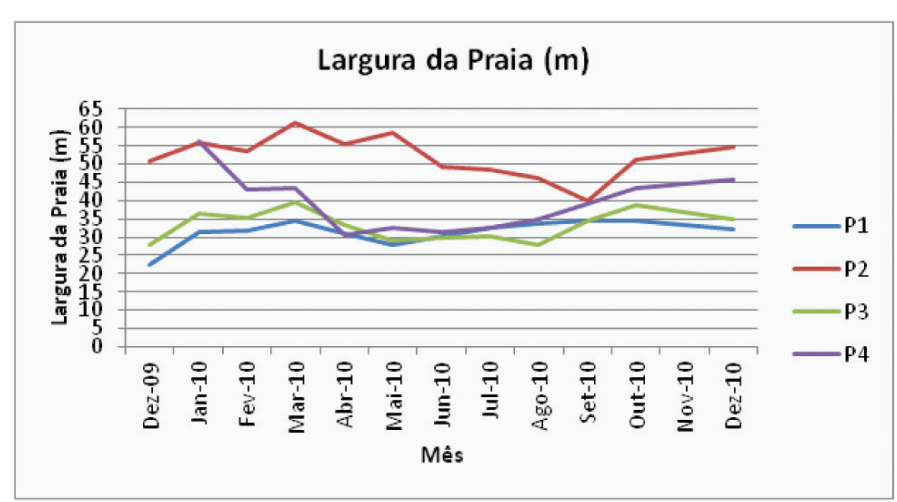

Figura 5. Variação da largura da faixa de praia medido nos perfis durante o período de monitoramento.

Figure 5. Beach widths variation measured on profiles during the monitoring period.

(Bittencourt et al., 2005), ao fato deste está localizado numa área estuarina, à margem esquerda do rio Maracaípe, onde a dinâmica sedimentar é diferenciada pela hidrodinâmica do rio. Macêdo et al. (2010) observou que os índices de chuva na regiáo para o período foram acima da média ocasionando o aumento da vazão dos rios costeiros, concomitantemente, podendo ter contribuído na erosão das margens do estuário atingindo às praias adjacentes. Nos meses de março a maio de 2010 todos os perfis apresentaram tendência erosiva em sua largura e volume com leves variaçóes positivas para P2 e P4.

A partir de junho/2010 o P1 começa a aumentar sua faixa de praia e se estabiliza nos meses seguintes com uma média de 32,98 m de largura até o final do monitoramento.
De junho a setembro de 2010 o perfil 2 apresentou um comportamento contrário com uma forte tendência retrogradante. À medida que isto acontece P3 e P4 apresenta um alargamento, ou seja, o padrão de deposição que antes indicava de sul para norte agora ocorre de modo inverso, de norte para sul. Do mês de outubro a dezembro de 2010 ocorrem tendências divergentes entre os 4 perfis. P1 apresentou um ligeiro estreitamento em sua faixa de praia, cerca de $2 \mathrm{~m}$, ao passo que em P2 houve um aumento em sua largura da mesma ordem que P1. Para os perfis a sul, P3 e P4, também ocorreram estreitamento e alargamento da praia, respectivamente. Em P3 o estreitamento foi de 3,6 m enquanto que em P4 o aumento foi de $2,3 \mathrm{~m}$.

\subsection{Parâmetros de Ondas}

A altura da onda na arrebentaçáo $\left(\mathrm{H}_{\mathrm{b}}\right)$ foi distinta para os pontos monitorados (Tabela 2) em função dos processos físicos de difração e refração onde havia recifes, pois em alguns trechos os arenitos ficam submersos durante a preamar. $\mathrm{O}$ perfil 1 é caracterizado por uma área com arrebentação de ondas dos tipos deslizante e mergulhante, com altura média de $0,7 \mathrm{~m}$. No período seco as ondas apresentaram $\mathrm{H}_{\mathrm{b}}$ média de $0,76 \mathrm{~m}$ e no período chuvoso $0,62 \mathrm{~m}$. Já o P2 obteve altura média de 1,55 m no período seco e 1,62 m durante o período chuvoso e ondas com arrebentaçáo predominantemente do tipo mergulhante. O P3 apresentou médias de $\mathrm{H}_{\mathrm{b}}$ de $1,58 \mathrm{~m}$ e 1,60 m para os dois períodos do ano, muito semelhante às medidas no P2. No P4 às médias de $\mathrm{H}_{\mathrm{b}}$ se assemelham ao $\mathrm{P} 1$, sendo significativamente um pouco maiores, $0,85 \mathrm{~m}$ e 0,78 $\mathrm{m}$, para os períodos seco e chuvoso, respectivamente.

Percebe-se que há dados semelhantes da altura das ondas na arrebentaçáo para pontos distintos, no caso, temos $\mathrm{P} 1 \mathrm{e}$ P4 como também em P2 e P3. Isto pode ser explicado pelo

Tabela 2. Altura da onda na arrebentação $\left(\mathrm{H}_{\mathrm{b}}\right)$ em metros e tipo de quebra da onda.

Table 2. Wave breaking height $\left(H_{b}\right)$ in meters and wave breaking type.

\begin{tabular}{l|l|l|l|l}
\hline & \multicolumn{4}{l}{ Perfil } \\
\hline Mês/Ano & P1 & P2 & P3 & P4 \\
\hline Jan/10 & 0,6 & 1,2 & 1,4 & 0,5 \\
\hline Fev/10 & 0,7 & 1,4 & 1,2 & 0,8 \\
\hline Mar/10 & 0,5 & 1,4 & 1,3 & 0,7 \\
\hline Abr/10 & 1,0 & 1,8 & 1,9 & 1,0 \\
\hline Mai/10 & 0,9 & 1,5 & 1,7 & 1,1 \\
\hline Jun/10 & 0,9 & 1,9 & 2,0 & 1,0 \\
\hline Jul/10 & 0,9 & 1,9 & 1,7 & 0,9 \\
\hline Ago/10 & 0,5 & 1,4 & 1,2 & 0,6 \\
\hline Set/10 & 1,1 & 2,1 & 2,0 & 0,9 \\
\hline Out/10 & 0,3 & 1,7 & 1,7 & 0,7 \\
\hline Nov/10 & 0,3 & 1,0 & 1,4 & 0,8 \\
\hline Arrebentaçáo & $\begin{array}{l}\text { Deslizante e } \\
\text { Mergulhante }\end{array}$ & Mergulhante & $\begin{array}{l}\text { Mergulhante e } \\
\text { Ascendente }\end{array}$ & Deslizante \\
\hline
\end{tabular}


Tabela 3. Dados dos parâmetros granulométricos. PP = Pós-praia; ES = Estirâncio

Table 3. Granulometric parameters data. $P P=$ Backshore; $E S=$ Foreshore

\begin{tabular}{|c|c|c|c|c|c|c|c|c|c|c|}
\hline Perfil & $\begin{array}{l}\text { Data } \\
\text { (Mês/ } \\
\text { Ano) }\end{array}$ & Amostra & $\begin{array}{l}\text { Média } \\
(\Phi)\end{array}$ & Classificação & $\begin{array}{l}\text { Seleçáa } \\
(\boldsymbol{\sigma})\end{array}$ & Classificaçãoo & Assimetria & Classificação & $\begin{array}{l}\text { Areia } \\
(\%)\end{array}$ & $\begin{array}{l}\text { Finos } \\
(\%)\end{array}$ \\
\hline \multirow{12}{*}{ P1 } & \multirow{2}{*}{$12 / 09$} & $\mathbf{P P}$ & 2,3 & Areia Fina & 0.5 & Moderadamente Selecionado & -0.46 & Muito Negativa & 99.46 & 0.52 \\
\hline & & ES & 1,9 & Areia Média & 0.6 & Moderadamente Selecionado & 0.28 & Positiva & 98.75 & 1.25 \\
\hline & \multirow{2}{*}{$01 / 10$} & PP & 2,3 & Areia Fina & 0.5 & Moderadamente Selecionado & -0.37 & Muito Negativa & 99.54 & 0.46 \\
\hline & & ES & 2,7 & Areia Média & 0.8 & Moderadamente Selecionado & -0.02 & Aproximadamente Simétrica & 97.47 & 2.35 \\
\hline & \multirow{2}{*}{$02 / 10$} & PP & 2,4 & Areia Fina & 0.4 & Bem Selecionado & -0.56 & Muito Negativa & 99.65 & 0.33 \\
\hline & & ES & 2,7 & Areia Fina & 0.4 & Bem Selecionado & 0.04 & Aproximadamente Simétrica & 98.52 & 1.48 \\
\hline & \multirow{2}{*}{$06 / 10$} & $\mathbf{P P}$ & 2,3 & Areia Fina & 0.5 & Moderadamente Selecionado & -0.43 & Muito Negativa & 100 & 0 \\
\hline & & ES & 2,1 & Areia Fina & 0.5 & Moderadamente Selecionado & 0.40 & Muito Positiva & 99.32 & 0.68 \\
\hline & \multirow{2}{*}{$07 / 10$} & PP & 2,3 & Areia Fina & 0.5 & Moderadamente Selecionado & -0.43 & Muito Negativa & 99.56 & 0.43 \\
\hline & & ES & 2,3 & Areia Fina & 0.5 & Moderadamente Selecionado & -0.49 & Muito Negativa & 98.86 & 1.13 \\
\hline & \multirow{2}{*}{$08 / 10$} & $\mathbf{P P}$ & 2,1 & Areia Fina & 0.5 & Moderadamente Selecionado & 0.44 & Muito Positiva & 99.75 & 0.25 \\
\hline & & ES & 2,0 & Areia Fina & 0.6 & Moderadamente Selecionado & 0.26 & Positiva & 99.04 & 0.87 \\
\hline \multirow{12}{*}{ P2 } & \multirow{2}{*}{$12 / 09$} & PP & 1,7 & Areia Média & 0.4 & Bem Selecionado & 0.01 & Aproximadamente Simétrica & 99.94 & 0 \\
\hline & & ES & 1,9 & Areia Média & 0.6 & Moderadamente Selecionado & 0.28 & Positiva & 98.75 & 1.25 \\
\hline & \multirow{2}{*}{$01 / 10$} & PP & 1,7 & Areia Média & 0.3 & Bem Selecionado & 0.05 & Aproximadamente Simétrica & 99.9 & 0.1 \\
\hline & & ES & 1,3 & Areia Média & 0.6 & Moderadamente Selecionado & -0.14 & Negativa & 99.63 & 0.37 \\
\hline & \multirow{2}{*}{$02 / 10$} & PP & 1,7 & Areia Média & 0.4 & Bem Selecionado & 0.04 & Aproximadamente Simétrica & 99.42 & 0.58 \\
\hline & & ES & 1,4 & Areia Média & 0.5 & Moderadamente Selecionado & -0.50 & Muito Negativa & 99.3 & 0.70 \\
\hline & \multirow{2}{*}{$06 / 10$} & PP & 1,7 & Areia Média & 0.4 & Bem Selecionado & 0.01 & Aproximadamente Simétrica & 99.62 & 0.38 \\
\hline & & ES & 2,0 & Areia Fina & 0.5 & Moderadamente Selecionado & 0.53 & Muito Positiva & 99.49 & 0.51 \\
\hline & \multirow{2}{*}{$07 / 10$} & PP & 1,7 & Areia Média & 0.4 & Bem Selecionado & -0.01 & Aproximadamente Simétrica & 99.66 & 0.34 \\
\hline & & ES & 1,8 & Areia Média & 0.7 & Moderadamente Selecionado & 0.02 & Aproximadamente Simétrica & 99.07 & 0.93 \\
\hline & \multirow{2}{*}{$08 / 10$} & $\mathbf{P P}$ & 1,7 & Areia Média & 0.4 & Bem Selecionado & 0.01 & Aproximadamente Simétrica & 99.67 & 0.33 \\
\hline & & ES & 1,7 & Areia Média & 0.7 & Moderadamente Selecionado & 0.01 & Aproximadamente Simétrica & 98.57 & 1.43 \\
\hline \multirow{12}{*}{ P3 } & \multirow{2}{*}{$12 / 09$} & PP & 1,1 & Areia Média & 0.5 & Moderadamente Selecionado & 0.40 & Muito Positiva & 99.33 & 0.32 \\
\hline & & ES & 2,0 & Areia Fina & 0.5 & Moderadamente Selecionado & 0.54 & Muito Positiva & 98.92 & 1.08 \\
\hline & \multirow{2}{*}{$01 / 10$} & PP & 1,5 & Areia Média & 0.6 & Moderadamente Selecionado & -0.26 & Negativa & 99.32 & 0.68 \\
\hline & & ES & 1,6 & Areia Média & 0.8 & Moderadamente Selecionado & 0.01 & Aproximadamente Simétrica & 99.22 & 0.57 \\
\hline & \multirow{2}{*}{$02 / 10$} & PP & 1,3 & Areia Média & 0.5 & Moderadamente Selecionado & -0.40 & Muito Negativa & 99.77 & 0.13 \\
\hline & & ES & 1,5 & Areia Média & 0.6 & Moderadamente Selecionado & -0.25 & Negativa & 99.52 & 0.48 \\
\hline & \multirow{2}{*}{$06 / 10$} & PP & 1,5 & Areia Média & 0.5 & Moderadamente Selecionado & -0.30 & Muito Positiva & 99.6 & 0.40 \\
\hline & & ES & 2,0 & Areia Fina & 0.5 & Moderadamente Selecionado & 0.29 & Negativa & 99.01 & 1.00 \\
\hline & \multirow{2}{*}{$07 / 10$} & PP & 1,4 & Areia Média & 0.6 & Moderadamente Selecionado & -0.22 & Negativa & 99.06 & 0.86 \\
\hline & & ES & 1,9 & Areia Média & 0.6 & Moderadamente Selecionado & 0.26 & Positiva & 99.11 & 0.89 \\
\hline & \multirow{2}{*}{$08 / 10$} & PP & 2,0 & Areia Fina & 0.6 & Moderadamente Selecionado & 0.26 & Positiva & 99.7 & 0.30 \\
\hline & & ES & 1,1 & Areia Média & 0.6 & Moderadamente Selecionado & 0.59 & Muito Positiva & 98.68 & 1.32 \\
\hline
\end{tabular}


Tabela 3 (continuação). Dados dos parâmetros granulométricos. PP = Pós-praia; ES = Estirâncio

Table 3 (continuation). Granulometric parameters data. $P P=$ Backshore; $E S=$ Foreshore

\begin{tabular}{|c|c|c|c|c|c|c|c|c|c|c|}
\hline \multirow{12}{*}{ P4 } & \multirow[b]{2}{*}{$12 / 09$} & PP & 2,9 & Areia Fina & 0.6 & Moderadamente Selecionado & 0.26 & Positiva & 99.1 & 0.90 \\
\hline & & ES & 3,0 & $\begin{array}{l}\text { Areia Muito } \\
\text { Fina }\end{array}$ & 0.6 & Moderadamente Selecionado & 0.29 & Positiva & 97.26 & 2.74 \\
\hline & \multirow{2}{*}{$01 / 10$} & PP & 2,4 & Areia Fina & 0.5 & Moderadamente Selecionado & -0.28 & Negativa & 99.30 & 0.70 \\
\hline & & ES & 2,5 & Areia Fina & 1.3 & Pobremente Selecionado & -0.29 & Negativa & 92.26 & 7.15 \\
\hline & \multirow{2}{*}{$02 / 10$} & PP & 2,4 & Areia Fina & 0.6 & Moderadamente Selecionado & -0.28 & Negativa & 99.68 & 0.32 \\
\hline & & ES & 2,9 & Areia Fina & 0.9 & Moderadamente Selecionado & 0.03 & Aproximadamente Simétrica & 88.2 & 11.68 \\
\hline & \multirow{2}{*}{$06 / 10$} & PP & 2,7 & Areia Fina & 0.2 & Muito Bem Selecionado & -0.26 & Negativa & 99.56 & 0.44 \\
\hline & & ES & 2,1 & Areia Fina & 0.7 & Moderadamente Selecionado & 0.30 & Muito Positiva & 98.1 & 1.89 \\
\hline & \multirow{2}{*}{$07 / 10$} & PP & 2,7 & Areia Fina & 0.3 & Bem Selecionado & 0.06 & Aproximadamente Simétrica & 99.19 & 0.82 \\
\hline & & ES & 2,5 & Areia Fina & 0.5 & Moderadamente Selecionado & -0.29 & Negativa & 98.35 & 1.53 \\
\hline & \multirow[b]{2}{*}{$08 / 10$} & PP & 2,7 & Areia Fina & 0.2 & Muito Bem Selecionado & -0.27 & Aproximadamente Simétrica & 98.82 & 1.18 \\
\hline & & ES & 3,0 & $\begin{array}{l}\text { Areia Muito } \\
\text { Fina }\end{array}$ & 0.7 & Moderadamente Selecionado & 0.14 & Negativa & 95.16 & 4.61 \\
\hline
\end{tabular}

fato de P1 e P4 serem regiōes de praias protegidas por recifes que existem na plataforma interna. Segundo Black (2001) as ondas perdem sua altura ao serem difratadas nos recifes, por isso estes dois perfis localizados nos trechos extremos, norte e sul, possuem ondas com baixa altura na arrebentação. Já no caso dos perfis $\mathrm{P} 2$ e $\mathrm{P} 3$ por estarem situados em áreas de mar aberto não há interferência dos recifes na aproximação das ondas, logo, estas arrebentam diretamente na face de praia onde dissipam sua energia. Os períodos de maior altura de onda $\left(\mathrm{H}_{\mathrm{b}}\right)$ ocorreram entre os meses de abril a setembro.

\subsection{Análise Sedimentológica}

Os dados das análises granulométricas estão disponíveis na Tabela 3 com os parâmetros abordados neste trabalho (diâmetro médio, seleção e assimetria). As 48 amostras apresentaram teores de areia que variam de $88,2 \%$ a $100 \%$ com o restante nas fraçóes finas (silte + argila). $\mathrm{O}$ diâmetro médio de todas as amostras varia de $1,1 \Phi$ a 3,0Ф (areia média a muito fina) com os percentuais das distribuiçôes granulométricas compostas por: $50 \%$ de areia fina, seguido por $45,8 \%$ de areia média e $4,2 \%$ de areia muito fina. A fração areia fina prevalece nos setores 1 e 4 enquanto que nos setores 2 e 3 predomina a fração areia média. A semelhança no diâmetro entre estes setores se deve às condiçôes hidrodinâmicas a que estão expostos. Os setores 1 e 4 encontram-se protegidos por linhas de recifes que dissipam parcialmente a energia das ondas incidentes propiciando a sedimentação de fraçóes mais finas já que há pouca turbulência. Os setores 2 e 3 localizam-se na parte central da praia de Maracaípe que é exposta ao mar aberto, onde as ondas arrebentam diretamente na praia, transportando e depositando sedimentos mais grossos.

As variaçōes do diâmetro médio das amostras ocorreram praticamente apenas no estirâncio em $\mathrm{P} 1$, de areia média para fina; $\mathrm{P} 3$ de areia fina pra média e; $\mathrm{P} 4$ de areia fina para muito fina em determinados meses de amostragem.

O valor do grau de seleçáo apresentou variaçấo de 0,2 a 1,3 sendo que do total $75 \%$ dos sedimentos foram classificados como moderadamente selecionado, $18,8 \%$ bem selecionados, $4,2 \%$ muito bem selecionado e $2 \%$ pobremente selecionado. Segundo Sahu (1964), o desvio padrão mede o nível de seleção dos sedimentos, indicando as flutuaçóes do nível energético do agente responsável pela deposição. A predominância de valores de seleção moderada indica que os sedimentos são frequentemente retrabalhados (deposição e sedimentação) pelo agente de transporte (Masselink \& Hughes, 2003). Neste caso o principal agente selecionador dos grãos são as ondas. Também observa-se que as amostras classificadas como bem e muito bem selecionadas foram coletadas na póspraia (P1, P2 e P4 - Tabela 3) podendo-se associar a ação do vento como principal agente selecionador nesta morfologia do perfil como afirmaram Figueiredo \& Calliari (2006) . Para Tabajara \& Martins (2006) as forças e velocidades constantes dos ventos promovem a depleçáo da berma e da praia exposta, transportando as areias para as partes superiores da praia que se depositam na barreira natural exercida pela vegetação. De fato, observa-se esta relação no setor 3 onde fica o P3 que é o trecho mais afetado pela ocupação no póspraia que impede a regeneração da vegetação na área, por isso, não ocorreu um melhor grau de seleçáo. Por outro lado, no P2 onde há uma melhor preservação da vegetação praial, apresentou todas as suas amostras da pós-praia como bem selecionadas. A única amostra classificada como pobremente selecionada pertence ao estirâncio do $\mathrm{P} 4$ onde visualizou-se uma pequena quantidade de material bioclástico que talvez tenha causado uma pequena flutuação dos valores.

Os resultados da assimetria variam de 0,59 a $-0,50$, desde muito positiva a muito negativa. Cerca de $29,2 \%$ das amostras foram classificadas como aproximadamente simétrica, $23 \%$ negativa, $16,7 \%$ muito positiva, $16,5 \%$ muito negativa e $14,6 \%$ positiva. Valores negativos da assimetria geralmente indicam granulaçóes mais grossas na distribuição granulométrica (Masselink \& Hughes, 2003) de modo que assimetria positiva indica granulação mais fina. Valores negativos sáo relacionados a sedimentos de praia, Duane (1964), Friedman (1961, 1967, 1979), Folk (1966) 
e Hails (1967). Por outro lado, vários são também os autores que não identificaram qualquer correlação dos valores de assimetria negativa e processos de deposição na face praial, Shepard \& Young (1961), Moiola \& Weiser (1968), Solohub \& Klovan (1970), Chakrabarti (1977), Martins (1965) e McLaren (1981). Para Masselink \& Hughes (2003) o aumento dos valores da assimetria estáo condicionados a mistura dos sedimentos de diferentes fontes.

Friedman (1961) ao estudar as características texturais dos sedimentos de dunas, praias e rios, conseguiu distinguilos por meio da relaçáo entre o grau de assimetria e o desvio padrão. Hails (1967) e Friedman (1961) observaram que, em geral, a tendência de sedimentos fluviais é de possuir assimetria positiva e o grau de seleção pode variar de bem a mal selecionado ao passo que os sedimentos marinhos possuem assimetria negativa e bom grau de seleção. Na presente área de estudo, apesar de ser uma enseada com pouco mais de $3 \mathrm{~km}$ de extensão, em períodos de maior descarga fluvial, há uma maior quantidade de sedimentos finos oriundos do Rio Maracaípe que sáo levados por deriva à praia adjacente (Macêdo et al., 2010).

\subsection{Variaçóes da Linha de Costa em Curto Prazo}

A linha de costa apresentou uma grande variação morfológica para cada ponto monitorado de Maracaípe. As diversas linhas d'água vetorizadas sobrepostas (Figura 6) permitiram identificar o padrão ou tendência de mobilidade da costa. Tomando-se como base a linha de costa da imagem datada de 01/09/2009, a mais antiga do estudo, foi realizada medidas por transectos que mensurassem as respectivas variações das linhas de costa de datas subseqüentes.

O perfil 1 apresentou a menor variação entre os demais pontos monitorados (Tabela 4). Isto ocorre devido à zona de sombra formada pelos recifes levando esta área a ser uma das regióes mais estáveis de todo o perímetro praial. O acumulado histórico para este ponto foi negativo não sendo tão significativo frente ao curto período monitorado. Os perfis 2,3 e 4 apresentaram as maiores variaçóes, sendo que o P2 e P3 mostraram tendências progradantes e retrogradantes semelhantes. Ambos acresceram entre setembro e outubro de 2009 enquanto que entre outubro de 2009 a fevereiro de 2010 o acumulado foi negativo, da ordem de $-11,88 \mathrm{~m} \mathrm{e}-10,44$ para P2 e P3, respectivamente. Nos meses entre fevereiro e junho de 2010 os perfis progradaram recuperando suas faixas de praias variando dentro do desvio padrão calculado.

No período completo o saldo foi positivo com uma faixa de praia mais larga que a inicial para estas porçóes centrais da praia (P2 e P3). O perfil 4 registrou recuo em todos os intervalos de tempo. Em pouco mais de um mês (setembro a outubro de 2009) esta regiáo do P4 recuou $-10,62 \mathrm{~m}$. De outubro de 2009 a fevereiro de 2010 o recuo foi maior $(-23,73 \mathrm{~m})$, mas com uma taxa mensal menor que o período anterior. Entre fevereiro e junho de 2010 houve uma erosão de $-12,83 \mathrm{~m}$, semelhante ao primeiro período estudado, com uma retração total de $-47,02 \mathrm{~m}$ para todo o período de estudo.

Atenta-se ao fato que estes valores indicam medidas subjetivas devido à influência de vários fatores naturais que podem atuar na variação do indicador escolhido, que, no
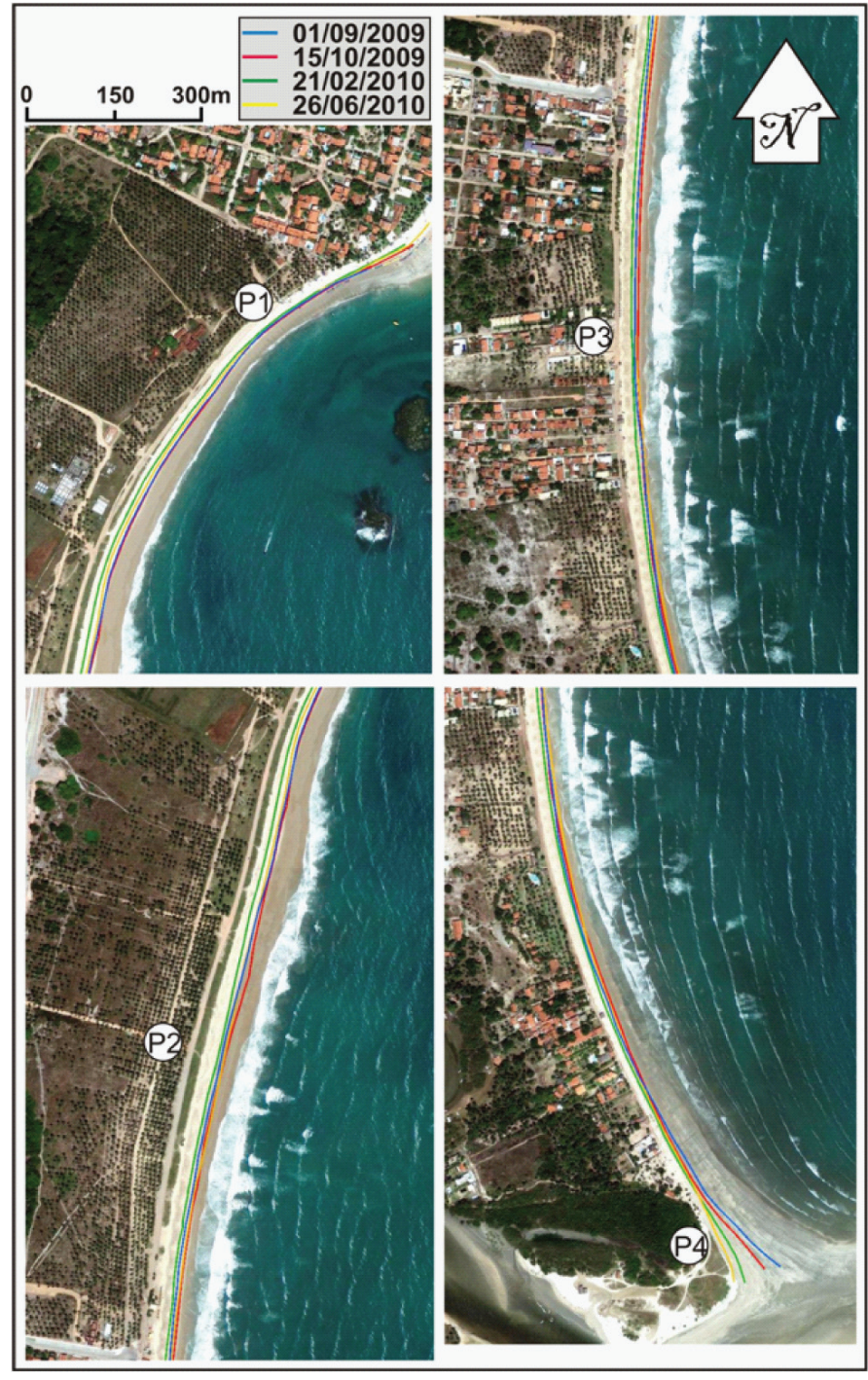

Figura 6. Evolução da linha de costa de curto prazo. Imagens obtidas do Google Earth.

Figure 6. Coastline evolution in short term. Courtesy from Google Earth.

presente trabalho, foi a interface entre a zona seca e úmida da praia. Segundo Stive et al. (2002) estes indicadores de linha de costa variam no espaço a curto prazo. Estes autores consideram como causas: ondas, marés e tempestades, bem como variações sazonais climáticas. Além disso, a avaliação da variação histórica da linha de costa por transectos pode levar a uma incerteza devido à possibilidade dos pontos escolhidos não representar a média total de mudança da costa estudada (Boak \& Turner, 2005). Se comparados os dados entre as variaçóes da linha de costa e largura da praia não teremos congruências nos resultados. Por exemplo, temos para P1 entre dezembro de 2009 e fevereiro de 2010, nos dados de largura de praia, a tendência progradante da praia, ao passo que se observou um recuo da linha de costa para o mesmo período nas imagens aéreas. Apesar das incertezas apontadas podemos identificar que estas variaçôes estão relacionadas diretamente com o clima de ondas de cada período. Stive et al. (2002) aponta que em monitoramentos de curto prazo estas mudanças no perfil praial estâo relacionadas ao clima 
Tabela 4. Variação da linha de costa em curto prazo em metros (m). Valores negativos significam erosão. Table 4. Short term coastline variation in meters $(m)$. Negative values means erosion.

\begin{tabular}{|c|c|c|c|c|c|c|}
\hline \multirow[b]{2}{*}{ Perfil } & \multicolumn{3}{|l|}{ Período } & \multirow{2}{*}{$\begin{array}{l}\text { Desvio } \\
\text { Padráo ( }(\sigma)\end{array}$} & \multicolumn{2}{|l|}{ Total } \\
\hline & $\begin{array}{l}01 / 09 / 2009 \text { e } \\
15 / 10 / 2009\end{array}$ & $\begin{array}{l}15 / 10 / 2009 \text { e } \\
21 / 02 / 2010\end{array}$ & $\begin{array}{l}21 / 02 / 2010 \text { e } \\
26 / 06 / 2010\end{array}$ & & $\begin{array}{ll}01 / 09 / 2009 & \text { e } \\
26 / 06 / 2010 & \end{array}$ & $\begin{array}{l}\text { Variaçáo média } \\
\text { mensal (m) }\end{array}$ \\
\hline P1 & 1.53 & -4.96 & 2.49 & 4.05 & -0.96 & -0.096 \\
\hline P2 & 6.4 & -11.88 & 10.65 & 11.97 & 5.12 & 0.51 \\
\hline P3 & 5.54 & -10.44 & 7.37 & 9.79 & 2.5 & 0.25 \\
\hline P4 & -10.62 & -23.73 & -12.83 & 7.01 & -47.02 & -4.70 \\
\hline
\end{tabular}

de ondas intersazonal e até interanual. Na Figura 7, ao analisarmos o histórico da linha de costa no P1 a variação é a menor possível. Na medida em que nos afastamos de P1 em direção ao $\mathrm{P} 2$ o comportamento da linha de costa muda significativamente até chegarmos em $\mathrm{P} 4$.

Nas campanhas realizadas in lócus vimos que a face de praia tende a inclinaçóes suaves nos extremos da costa, P1 e P4, e mais íngremes nas regióes centrais, P2 e P3. É perceptível observar que os estados morfodinâmicos influenciam diretamente nessas flutuaçóes da linha d'água. Segundo a classificação dos estados praiais de Wright $\&$ Short (1984) o estado dissipativo apresenta um perfil suave, os intermediários variam desde suaves a inclinados e o reflectivo bem íngremes. As variaçóes horizontais das linhas históricas estudadas foram maiores em perfis mais íngremes enquanto que ocorre menor movimento em perfis suaves. A exceção foi no perfil 4 que mesmo com uma morfologia apresentando inclinação suave obteve a maior diferença entre as linhas de costa. Isto decorre da sua localização geográfica adjacente ao estuário pela interferência das variaçốes de maré e vazão do rio.
Os 4 transectos estudados sobre cada perfil mostraram dinâmicas pontuais de sedimentação. Porém, numa visualização geral das linhas históricas observa-se que os padrōes de acreção e erosão são muito mais complexos que os dispostos quantitativamente. Num olhar minucioso na Figura 7 (P1, P2 e P3) percebe-se que as linhas históricas se cruzam ora recuando em direção à costa ora avançando em direção ao mar. Crowell et al. (1993) apontam que esta flutuação no comportamento da linha costa resulta de vários fatores como migração de ondas de areia por deriva ou formação de megacúspides. Dean \& Dalrymple (2004) afirmam que essas mudanças correspondem ao transporte transversal à praia (transporte cross-shore e correntes de undertow) induzido por correntes de deriva. Estes fatores também podem indicar que a sedimentação na praia de Maracaípe ocorre em pequenas células costeiras com intercalações de erosão e progradação. Mazzer et al. (2009) identificaram várias células costeiras em 5 praias estudadas do litoral catarinense em Florianópolis (Brasil) a partir de duas variáveis - distribuição da energia de onda ao longo da costa e de parâmetros morfotexturais da face praial e seus sedimentos.
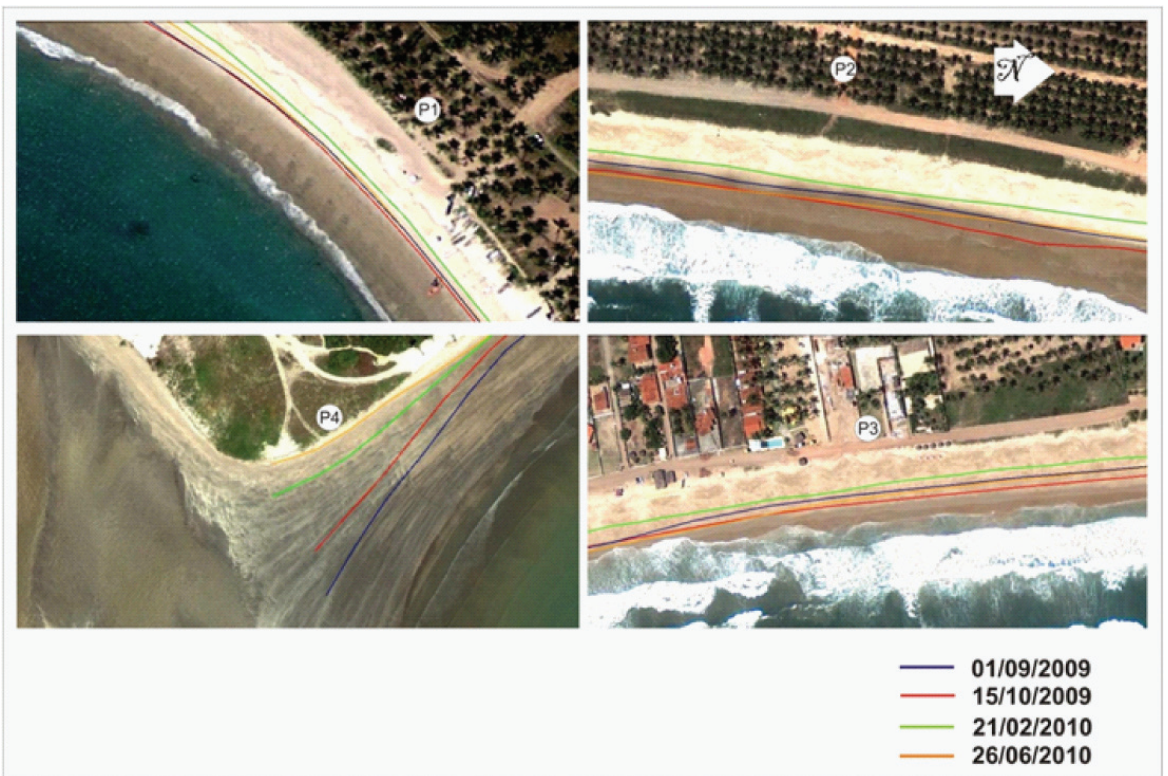

Figura 7. Linhas de costa em cada ponto analisado.

Figure 7. Shorelines of each point analised. 


\section{CONCLUSÃO}

A praia de Maracaípe apresenta distintos comportamentos morfológicos ao longo de sua orla. Os setores extremos, norte e sul (setor 1 e 4), encontram-se sob um regime de energia hidrodinâmica menor que os demais setores por estarem protegidos por recifes. $\mathrm{O}$ setor 1 apresenta baixa variação em sua largura de praia e em seu volume ocorrendo acreção durante o período seco e uma pequena erosáo no período chuvoso, no geral uma tendência progradante. $\mathrm{O}$ setor 4 possui maior variabilidade em sua morfologia e volume, com perda de sedimentos acentuada durante o período seco, mantendo uma certa estabilidade no meio do período de monitoramento e pequena acreção no final do estudo. Esta última, não foi suficiente para recuperar o volume perdido no final do verão. $\mathrm{O}$ contraste entre os períodos de erosão e deposição assim como a condição erosiva do setor 4 pode está relacionado à localização adjacente ao Rio Maracaípe e das forçantes atuantes neste setor (maré, ondas e correntes fluviais). Os setores centrais, 2 e 3 , estão expostos a um regime de maior energia hidrodinâmica, consequentemente, são os setores que apresentam amplas variaçôes morfológicas e de largura em seus perfis, principalmente o perfil 2. Os problemas de erosão recorrente no setor 3 relaciona-se com a ocupação irregular na faixa de praia. A relação dos dados entre volume e largura de praia não foram completamente congruentes, ou seja, nem sempre que ocorreu aumento de volume houve uma correspondente na largura. No entanto, quanto maior a largura da faixa de praia maior foi a variabilidade do volume, com exceção do setor 3 . Dois fatores importantes podem contribuir para essa relação, o primeiro seria o estado morfodinâmico e o segundo a fatores antrópicos, como observou-se no setor 3 pela construção de casas e hotéis na pós-praia. As larguras da faixa de praia indicaram que há uma predominância de transporte e deposição de sul para norte ao longo do ano, ocorrendo algumas inversões em determinados períodos (junho e setembro).

Os sedimentos são predominantemente compostos de areia média a fina, moderadamente a bem selecionada, sendo as granulaçóes mais finas nos setores extremos e as mais grossas nos centrais. Estas características sedimentológicas refletem as condiçóes morfodinâmicas inerentes de cada trecho da praia. A variação nos valores da assimetria indica que há ocorrência de sedimentos de fontes distintas. Neste caso, além da plataforma interna adjacente, o rio Maracaípe contribui como uma importante fonte de material siliciclástico às praias adjacentes.

No estudo da linha de costa em curto prazo, identificaramse padróes de deslocamentos diferenciados, havendo áreas em que a linha de costa recua e prograda intercaladamente, indiferente de setores, principalmente nos trechos centrais da praia. Isto decorre, possivelmente, da presença de células costeiras presentes numa escala menor do que a estudada no corrente trabalho. Portanto, necessita-se de estudos com uma malha de dados mais detalhadas, ou seja, com um maior número de setores para que haja uma representatividade maior para se entender mais claramente o transporte de sedimentos nesta regiáo da praia.
No geral, os processos erosivos observados na praia de Maracaípe estão associados a fatores antrópicos e naturais. $\mathrm{O}$ presente estudo se mostrou uma ferramenta importante para a compreensão da dinâmica morfossedimentar da praia de Maracaípe, fornecendo dados para os subsídios à gestão costeira da área no que tange o uso e ocupação da orla. Recomenda-se um monitoramento contínuo para se obter uma melhor compreensão da dinâmica costeira da área em médio e longo prazo a fim de se estabelecer limites de ocupação e uso da orla.

\section{AGRADECIMENTOS}

O primeiro autor é grato pela bolsa de mestrado concedida pelo Conselho Nacional de Desenvolvimento Científico e Tecnológico - CNPq, do Ministério da Ciência e Tecnologia do Brasil.

\section{BIBLIOGRAFIA}

Almeida, H.R.R.C. (2008) - Séries temporais de imagens suborbitais e orbitais de alta resolução espacial na avaliação da morfodinâmica praial no município do Cabo de Santo Agostinho - PE. Recife. 106p., Dissertação de Mestrado, Universidade Federal de Pernambuco, Recife, PE, Brasil. Não publicado.

Araújo, M.C.B.; Souza, S.T.; Chagas, A.C.O.; Barbosa, S.C.T.; Costa, M.F. (2007) - Análise da ocupação urbana das praias de Pernambuco, Brasil. Revista da Gestáo Costeira Integrada, 7(2):97-104. http://www.aprh.pt/ rgci/pdf/rgci7f2_2_mariaaraujo.pdf

Assis, H.M.B. (2007) - Influência da hidrodinâmica das ondas no zoneamento litorâneo e na faixa costeira emersa, entre Olinda e Porto de Galinhas, Pernambuco. 131 p., Tese de Doutorado, Universidade Federal de Pernambuco, Recife, PE, Brasil. Não publicado.

Bittencourt, A.C.S.P.; Dominguez, J.M.L.; Martin, L.; Silva, I.R. (2005) - Longshore transport on the northeastern Brazilian coast and implications to the location of large scale accumulative and erosive zones: An overview. Marine Geology, 219(4):219-234. DOI: 10.1016/j. margeo.2005.06.006

Black, K. (2001) - Artificial Surfing Reefs for Erosion Control and Amenity: Theory and application. Journal of Coastal Research, SI 34:1-14, New Zealand. Disponível em http://www.cerf-jcr.org/images/stories/Artificial Surfing Reefs for Erosion Control and Amenity_ Theory Application Kerry Black.pdf

Boak, E.H.; Turner, I.L. (2005) - Shoreline Definition and Detection: A Review. Journal of Coastal Research, 21(4):688-703. DOI: 10.2112/03-0071.1

Borba,A.L.S.(1999)-Estudossedimentológicos, morfodinâmicos e da vulnerabilidade das praias da piedade, candeias e barra das jangadas - município do Jaboatáo dos Guararapes-PE. 130p., Dissertação de mestrado, Universidade Federal de Pernambuco, Recife, PE, Brasil. Não publicado.

Camargo, M.G. (2006) - SYSGRAN: um sistema de código aberto para análises granulométricas do sedimento. Revista Brasileira de Geociências, 36(2):371-378. Disponível em: http://200.17.232.45/sysgran?action=AttachFile \&do=ge t\&target=sysgran.pdf 
Chakrabart, A. (1977) - Polymodal composition of beach sands from the east coast of India. Journal of Sedimentary Petrology, 47(2): 634-641.

Costa, M.F.; Araújo, M.C.B.; Silva-Cavalcanti, J.S.; Souza, S.T. (2008) - Verticalização da Praia de Boa Viagem (Recife, Pernambuco) e suas Consequências SócioAmbientais. Revista de Gestão Costeira Integrada, 8(2): 233-245.http://www.aprh.pt/rgci/pdf/RGCI-128_Ferreirada-Costa.pdf

Coutinho, P.N.; Lima, A.T.O; Queiroz, C.M.; Freire, G.S.S.; Almeida, L.E. S. B.; Maia, L.P.; Manso, V.A.V.; Borba, A.L.S.; Martins, M.H.A.; Duarte, R.X. (1997) - Estudo da erosão marinha nas praias de Piedade e de Candeias e no estuário de Barra de Jangadas. Município de Jaboatão dos Guararapes-PE. 154 p. + 3 mapas, Laboratório de Geologia e Geofísica Marinha-LGGM/UFPE, Relatório Técnico, Recife, PE, Brasil. Não publicado.

Cowell, P.J.; Thom B.G., (1997) - Morphodynamics of coastal evolution. In: R.W.G. Carter \& C.D. Woodroffe (eds.), Coastal evolution, Late Quaternary shoreline morphodynamics, pp.33-86, Cambridge University Press, Cambridge, U.K.. ISBN: 9780521598903

Cowell, P.J.; Stive, M.J.F.; Niedoroda, A.W.; Vriend, H.J.; Swift, D.J.P.; Kaminsky, G.M.; Capobianco, M. (2003) - The coastal-tract (Part 1): a conceptual approach to aggregated modeling of low-order coastal change. Journal of Coastal Research, 19(4):812-827.

Crowell, M., Leatherman, S.P., Buckley, M.K. (1993) Shoreline change rate analysis: long term versus short term data. Shore and Beach, 61(2):13-20.

Davies, J.L. (1964) - A morphogenic approach to world shorelines. Zeitschrift für Geomorphologie, 8:127-142.

Dean, R.G.; Dalrymple, R.A. (2004) - Coastal Processes with engineering applications. 488p., Cambridge University Press, Cambridge, U.K. ISBN: 9780521602754

Duane, D.B. (1964) - Significance of skewness in recent sediments, Western Pamlico Sound, North Carolina. Journal of Sedimentary Petrology, 34(4):864-874.

Figueiredo, S.A.; Calliari, L.J. (2006) - Sedimentologia e suas implicaçóes na morfodinâmica das praias adjacentes à desembocaduras da linha de costa do Rio Grande do Sul. Gravel (ISSN 1678-5975), 4:73-87, Poto Alegre, RS, Brasil. Disponível em: http://www.ceco.ufrgs.br/ gravel/4/CD/docs/Gravel_4_06.pdf

Folk, R.L.; Ward W.C. (1957) - Brazos river bar: a study of significance of grain size parameters. Journal of Sedimentary Petrology, 27(1):3-26.

Folk, R.L. (1966) - A review of grain-size parameters. Sedimentology, 6(2):73-93.

Friedman, G.M. (1961) - Distinction between dune, beach and river sands from their textural characteristics. Journal of Sedimentary Petrology, 31(4):15-25. DOI: 10.1306/74D70BCD-2B21-11D7-8648000102C1865

Friedman, G.M. (1967) - Dynamic processes and statistical parameters compared for size frequency distribution of beach and river sands. Journal of Sedimentary Petrology, 37(2):327-354. DOI: 10.1306/74D716CC-2B21-11D7$8648000102 \mathrm{C} 1865 \mathrm{D}$

Friedman, G.M. (1979) - Address of the retiring President of the International Association of Sedimentologists:
Diferences in size distributions of populations of particles among sands of various origins. Sedimentology, 26(1):332. DOI: 10.1111/j.1365-3091.1979.tb00336.x

Hails, J.R. (1967) - Significance of statistical parameters for distinguishing sedimentary environments in New South Wales, Australia. Journal of Sedimentary Petrology, 37(4):1059-1069. DOI: 10.1306/74D71834-2B21-11D7$8648000102 \mathrm{C} 1865 \mathrm{D}$

Klein, M.; Litcher, M. (2006) - Monitoring changes in shoreline position adjacent to Hadera power station, Israel. Applied Geography, 26(3-4):210-226. DOI: 10.1016/j.apgeog.2006.01.001

Macêdo, R.J.A.; Barreto, E.P.; Santos, A.C.; Manso, V.A.V. (2010) - Estudo Geoambiental da Orla de Maracaípe - Ipojuca (PE), Brasil. Revista Estudos Geológicos (ISSN 0367-0449), 20(2):93-111, Recife, PE,Brasil. Disponível em http://www.ufpe.br/estudosgeologicos

Macêdo, R.J.A. (2011) - Caracterização morfodinâmica e geoambiental da praia de Maracaipe, Ipojuca - PE. 143p., Dissertação de Mestrado, Universidade Federal de Pernambuco, Recife, PE, Brasil. Não publicado.

Madruga Filho, J.D. (2004) - Aspectos geoambientais entre as praias do Paiva e Gaibu, Municipio do Cabo de Santo Agostinho, litoral sul de Pernambuco. 234 p. + anexos, Tese de Doutorado, Universidade Federal de Pernambuco, Recife, PE, Brasil. Não publicado.

Manso, V.A.V. (2003) - Definição dos pontos de contorno da linha de preamar máxima atual do litoral do municipio de Ipojuca - PE. 34p., Relatório final, MMA/PNMA II - SECTMA No 249. Não publicado. Disponível em http://www.cprh.pe.gov.br/downloads/pnma2/relatoriofinal.pdf

Manso, V.A.V.; Corrêa, I.C.S.; Guerra, N.C. (2003) Morfologia e sedimentologia da plataforma continental interna entre as praias Porto de Galinhas e Campos - Litoral Sul de Pernambuco, Brasil. Pesquisas em Geociências, 30(2):17-25. Disponível em http://www. pesquisasemgeociencias.ufrgs.br/3002/02-3002.pdf

Manso, V.A.V.; Menor, E.A.; Valença, L.M.M.; Neumann, H.M.L.; Pereira, N.S.; Junior, C.F.A.S.; Silva, E.R.M. (2011) - Morfodinâmica de Praias Setentrionais da Ilha de Fernando de Noronha. Revista de Gestão Costeira Integrada, 11(3):327-339. DOI: $10.5894 /$ rgci239

Martins, L.R. (1965) - Significance of skewness and kurtosis in environmental interpretation. Journal of Sedimentary Petrology, 35(3):768-770.

Masselink, G., Short, A.D. (1993) - The effect of tide range on beach morphodynamics and morphology: a conceptual model. Journal of Coastal Research, 9(3):785-800.

Masselink, G., Hughes, M.G. (2003) - Introduction to coastal processes and geomorphology. 368p., Hodder Education Publishers, London, UK. ISBN: 9780340764114.

Moiola. R.J. \& Weiser, D. (1968) - Textural parameters: an evaluation. Journal of Sedimentary Petrology, 38: 45-53.

Muehe, D. (1996) - Geomorfologia Costeira. In: Sandra Baptista da Cunha; Antonio José Teixeira Guerra (org.), Geomorfologia - Exercícios, Técnicas e Aplicação. pp.191238, Bertrand Brasil, Rio de Janeiro, RJ, Brasil. ISBN: 8528605485 
Muehe, D. (coord.) (2006) - Erosão e progradação do litoral brasileiro. 476p., Ministério do Meio Ambiente, Brasília. DF, Brasil. ISBN: 8577380289. Disponível em http://www.mma.gov.br/estruturas/sqa_sigercom/_ publicacao/78_publicacao 12122008084856.pdf

Sahu, B.K. (1964) - Depositional mechanism from size analysis of clastic sediments. Journal of Sedimentary Petrology, 34(1):73-83. DOI:10.1306/74D70FCE2B21-11D7-8648000102C1865D.

Shepard, F.P.; Young, R. (1961) - Distinguishing between beach and dune sands. Journal of Sedimentary Petrology, 31(2):196-214. DOI: 10.1306/74D70B37-2B21-11D7$8648000102 \mathrm{C} 1865 \mathrm{D}$

Sobral, A.O.L. (1998) - Estudo da erosão marinha na região de Maracaipe - Ipojuca. 99p., CPRH - Agência Estadual de Meio Ambiente, Recife, PE, Brasil. Não Publicado.

Solohub, J.T.; Klovan, J.E. (1970) - Evaluation of grainsize parameters on Lacustrine environments. Journal of Sedimentary Petrology, 40(1):81-101. DOI: 10.1306/ 74D71EFB-2B21-11D7-8648000102C1865D.

Souza, C.R.G. (2007) - Determination of net shore-drift cells based on textural and morphological gradations along foreshore of sandy beaches. Journal of Coastal Research, SI50:620-625. Disponível em http://www.griffith.edu. au/conference/ics2007/pdf/ICS117.pdf
Souza, C.R.G. (2009) - A erosão costeira e os desafios da gestão costeira no Brasil. 2009. Revista de Gestão Costeira Integrada, 9(1):17-37. http://www.aprh.pt/rgci/pdf/rgci147_Souza.pdf

Stive, M.J.F.; Aarninkhof, S.G.J.; Hamm, L.; Hanson, H.; Larson, M.; Wijnberg, K.M.; Nicholls, R.J.; Capobianco, M. (2002) - Variability of shore and shoreline evolution. Coastal Engineering, 47(2):211-235. DOI: 10.1016/ S0378-3839(02)00126-6

Tabajara, L.L.; Martins, L.R. (2006) - Classificação textural de sedimentos praiais e a relaçáo com os processos morfogenéticos eólicos e marinhos. Gravel (ISSN 16785975), 4:99-107, Poto Alegre, RS, Brasil. Disponível em http://www.ufrgs.br/ceco/Gravel/4/cd/docs/gravel_4_08.pdf

Thom, B.G.; Short, A.D. (2006) - Introduction: Australian coastal geomorphology. Journal of Coastal Research, 22(1):1-10. DOI:10.2112/05A-0001.1

Toldo Jr., E.E.; Almeida, L.E.S.B.; Nicolodi, J.L.; Martins, L.R. (2005) - Retração e progradação da zona costeira do Estado do Rio Grande do Sul. Gravel (ISSN 16785975), 3:21-38, Poto Alegre, RS, Brasil. Disponível em http://www.ceco.ufrgs.br/Gravel/3/CD/docs/Gravel_3_04.pdf Wright, L.D.; Short, A.D. (1984) - Morphodynamics variability of surf zones and beaches: a synthesis. Marine Geology, 56(1-4):93-118. DOI: 10.1016/00253227(84)90008-2. 